
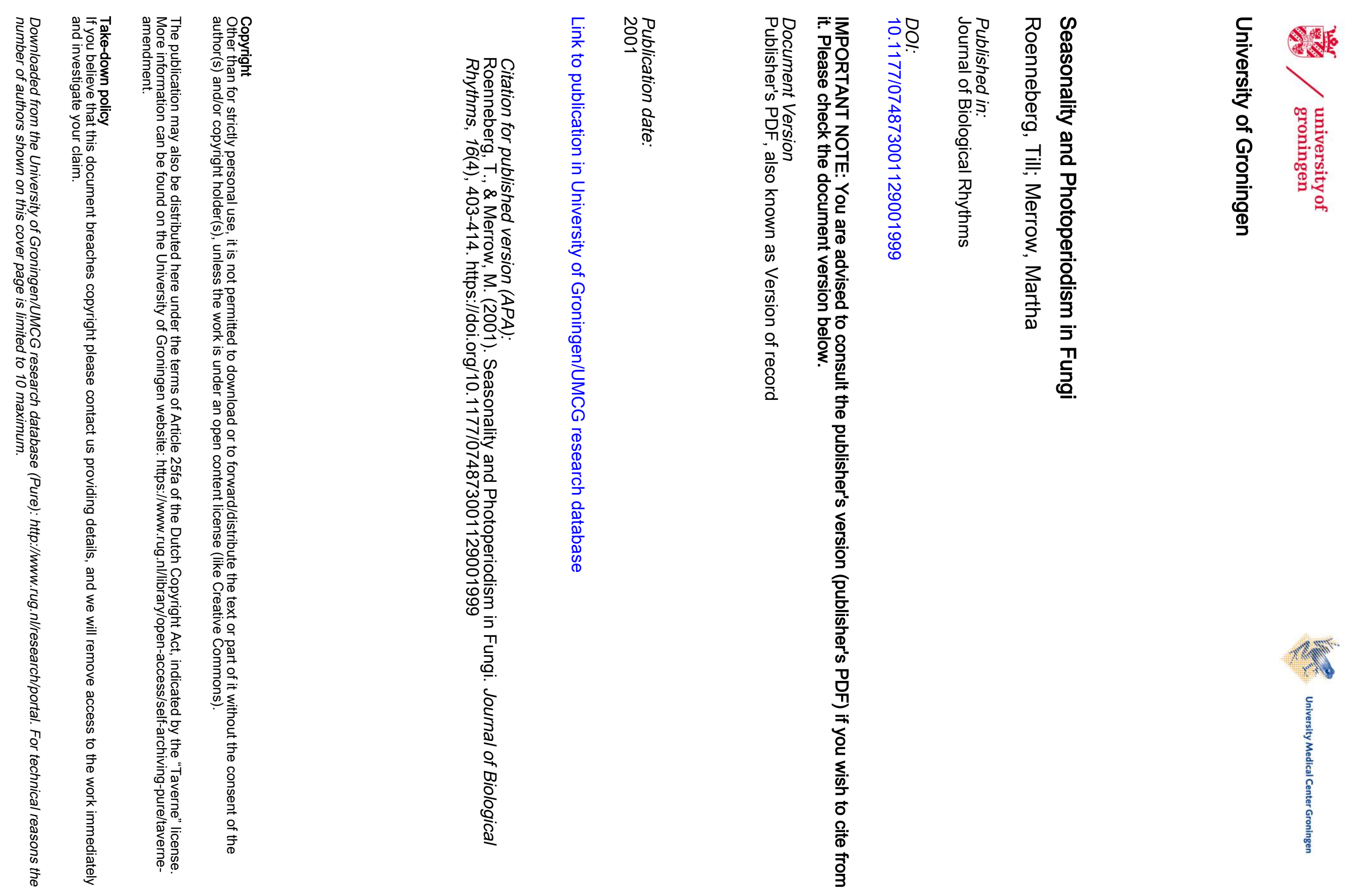


\title{
FUNGI
}

\section{Seasonality and Photoperiodism in Fungi}

\author{
Till Roenneberg ${ }^{1}$ and Martha Merrow \\ Institute for Medical Psychology, University of Munich, Goethestr. 31, 80336 Munich, Germany
}

\begin{abstract}
This review gives a retrospective of what is known about photoperiodism in fungi, which is largely based on reports about seasonal spore concentrations. Relatively few species have been investigated under laboratory conditions, so that our knowledge whether seasonal reproduction in fungi is mainly a direct response to environmental conditions or whether it involves a photoperiodic machinery with memory capacities and a relationship to the circadian system is extremely limited. To form a basis for further experimental endeavors into fungal photoperiodism, we review the reports about endogenous rhythms and photobiology. Finally, we will look at the possibilities of using the fungal circadian model system of Neurospora crassa for future work on photoperiodism.
\end{abstract}

Key words circadian, photoperiodic timer, photoperiodic memory, night length, Neurospora

Three chronobiologists were having beer and Schwammerl and Knödel ${ }^{*}$ in the famous Munich Schneiderbräu. Their conversation focused on rhythms and seasonality-how different the Bavarian beers were throughout the year: Starkbier in spring, Weißbier in summer, Wiesenbier in autumn, and Weihnachtsbier for the short days. Soon, the debate turned to yeast and the possibility of it also being different at different times of the year. But when one of them pointed out that yeast, at least the captive one used for brewing, had a lousy-if any - photobiology - "well, except for the odd photolyase with a transduction cascade for fixing up some UV-damaged gene" - the three scientists gave up the idea of explaining the differences in beers with the help of yeast photoperiodism. Yet, the stage was set, and after several silent minutes, the microbiologist among them came back to the basic question inherent in the earlier conversation. "What do we know about photoperiodism in fungi?" When there was no answer for some time, the microbiologist added, "And why would they need a photoperiodic

* Bavarian mushroom dish with dumplings. response in the first place?" This time, the answer was prompt, "S'pose, for the same reason as other organisms-to anticipate seasonal changes-mainly for reproduction." "So, why do we know so little about it?" Except for mumbled remarks by the animal and plant representatives, going in the direction of fungi having no testes to weigh and no leaves to count, the conversation moved to other matters.

It is quite surprising how little is known about photoperiodism in fungi. There are several reports of seasonality in fungi (see Seasonality and Photoperiodism in Fungi), but are they passive adaptations to seasonal changes or do they involve a photoperiodic mechanism? The circadian domain distinguishes between synchronization and entrainment, the former being a biological rhythm that is passively driven by environmental changes, the latter involving the active process of repetitive phase shifts resulting in a specific phase angle between an endogenous oscillation and a rhythmic environment. By analogy, seasonality can also be a driven process-a direct consequence of

1. To whom all correspondence should be addressed.

JOURNAL OF BIOLOGICAL RHYTHMS, Vol. 16 No. 4, August 2001 403-414

(C) 2001 Sage Publications 
environmental qualities: day or night length, temperature, and other climatic parameters such as humidity and rainfall, or even triggered by other organisms in the form of food and, in the case of pathogens, host availability. Alternatively, seasonality can be a consequence of an active process, or rather of two "interrelated processes" (Nunes and Saunders, 1999): (a) a timer that measures night length (rarely day length; see Saunders, 1982, 1987) and (b) some kind of memory that integrates the seasonal changes over time.

To approach the possibility of photoperiodism in fungi, we will review their photobiology, circadian systems, and seasonality of reproduction. Finally, we will integrate the details of the Neurospora system into possible molecular and genetic research on photoperiodism in fungi. The different fungi mentioned in the text are systematically listed in Table 1 (as well as some that are relevant but, due to space constraints, are not explicitly discussed).

\section{LIGHT RECEPTION IN FUNGI}

Without light reception, there is no photoperiodic response. Light regulates fungal reproduction (e.g., promotion of development or inhibition of germination; see Brook, 1969; Calpouzos and Chang, 1971; Degli-Innocenti and Russo, 1984; Durand, 1982; Ingold and Nawaz, 1967a), carotenoid or other pigment formation, and phototropism (Delbruck et al., 1976; Linden et al., 1999). Action spectra and/or fluence response curves have been determined for photoinhibition of spore maturation (Leach, 1968), carotenoid induction (see list in Berjarano et al., 1990; De Fabo et al., 1976), and phase-shifting circadian rhythms (Crosthwaite et al., 1995; Dharmananda, 1980; Sargent et al., 1956). Most of these photoresponses derive from the short end of the spectrum (sometimes including the UV region, e.g., reported for circadian phase shifting; see West, 1976). There are, however, also reports of red or far-red light responses in the fungi, among them asexual spore (conidia) formation in Aspergillus, which is regulated by both red and blue light (Mooney and Yager, 1990).

Are all fungi responsive to light? Notably absent from the catalog of photoresponsive fungi is Saccharomyces cerevisiae. Although decreased growth rate has been observed with increasing illumination in this yeast, the phenotype is generally weak and apparently occurs only at low temperatures (Edmunds et al., 1979b; Edmunds et al., 1978). In addition, cell division
Table 1. Taxonomy of fungi and protocista.

\begin{tabular}{|c|c|c|}
\hline Kingdom & Phylum & Genus \\
\hline \multirow[t]{7}{*}{ Protoctista } & Labyrinthilomycota & \\
\hline & Acrasiomycota & Dictyostelium \\
\hline & Myxomycota & \\
\hline & Plasmodiophoromycota & \\
\hline & Hypochytriodiomycota & \\
\hline & Chytriodiomycota & \\
\hline & Oomycota & Phytophthora \\
\hline \multirow[t]{28}{*}{ Fungi } & Zygomycota & Phycomyces \\
\hline & Ascomycota & Pilobolus \\
\hline & Ascomycota & Emericella \\
\hline & & (Aspergillus) \\
\hline & & Erysiphe \\
\hline & & Hypoxylon \\
\hline & & Mycosphaerella \\
\hline & & Neurospora \\
\hline & & Saccharomyces \\
\hline & & Schizosaccharomyces \\
\hline & & Sordaria \\
\hline & & Venturia \\
\hline & Basidiomycota & Armillaria \\
\hline & & Coprinus \\
\hline & & Pellicularia \\
\hline & & Sphaerobolus \\
\hline & & Ustilago \\
\hline & Deuteromycota-not a "real" & Alternaria \\
\hline & but a form phylum; the & Cercosporella \\
\hline & Deuteromycota (also & Cladosporium \\
\hline & called mitosporic fungi or & Colletotrichum \\
\hline & fungi imperfecti) contain & Exserohilum \\
\hline & species belonging either to & Fusarium \\
\hline & the Ascomycota or to the & Helminthosporium \\
\hline & Basidiomycota, which & Metarhizium \\
\hline & never appear to form & Pyricularia \\
\hline & sexual spores & Stemphylium \\
\hline & $\begin{array}{l}\text { Mycophycophyta Lichens- } \\
\text { fungi living in symbiosis } \\
\text { with cyanobacteria or } \\
\text { algae }\end{array}$ & \\
\hline
\end{tabular}

NOTE: The taxonomy of fungi is extremely complicated and differs depending on source and year. The systematic distribution of fungi in this table is based on Margulis and Schwartz (1988) and places several of the lower fungi in the kingdom of the Protoctista. For reasons of simplification, classes, orders, and families have been omitted. Genera that are mentioned in the text or the references are listed in the right column.

and amino acid transport in S. cerevisiae are synchronized to light:dark (LD) cycles in the circadian range (Edmunds et al., 1979a). Synchronization with LD cycles has also been reported for the fission yeast, Schizosaccharomyces pombe (Kippert et al., 1991b). Considering that wild-type $S$. cerevisiae are heterogeneous in their appearance relative to standard lab strains, it could be that robust photoresponsiveness was selected out, as occurred with Aspergillus (Mooney and Yager, 1990).

Although numerous light-regulated or lightdependent physiologies have been described for the 
fungi, in no case has the photoreceptor been characterized beyond action spectra, which generally indicate flavin-mediated blue light reception. On one hand, pharmacological experiments or experiments with mutants have suggested cytochrome b (Kippert et al., 1991a, 1991b) and molybdenum cofactors (Ninnemann, 1991) participating in light reception of fission yeast and Neurospora, respectively. On the other hand, mutagenesis experiments identified two loci in Neurospora, white-collar-1 and white-collar-2 (wc-1 and $w c-2)$, which control most photoresponses (Degli-Innocenti and Russo, 1984; Russo, 1988). The white-collar gene products are transcription factors, as judged by sequence analysis (Linden et al., 1999), and thus, if they prove to be part of the photoreceptive machinery, may participate in a manner similar to what has been indicated for PHYTOCHROME in plants (Martinez-Garcia et al., 2000). In addition, WC-1 has homology to the PAS/LOV domains of the plant NPH1 protein sequence, which is a blue-light photoreceptor in plants (Huala et al., 1997).

\section{CIRCADIAN AND DAILY RHYTHMS IN FUNGI}

A second requirement for photoperiodism-the assessment of the light or the dark period-entails a timer, which in plants and animals is generally linked to the circadian system. Perhaps the first indication of endogenous rhythms in the fungi derives from the dung-loving fungus Pilobolus, which shoots spores as far as $2 \mathrm{~m}$. Klein submitted Pilobolus to various symmetrical non-24-h LD cycles and found that the sporeshooting rhythm was absent in LD 4:4, 8:8, and 24:24 but had a large amplitude in LD 16:16, even larger than in any 24-h cycles with varying photoperiods (Klein, 1948). This series of experiments probably represents the first systematic investigation of the influence of photoperiod on the sporulation rhythm: Both short (LD 4:20) and long (LD 20:4) photoperiods appear to suppress rhythmicity, while it persists with a low amplitude in LD 9:15 and 15:9, and with a higher amplitude in LD 12:12.

The first article to prove the endogenous nature of this rhythmicity included experiments both in constant light (LL) and darkness (DD) (Schmidle, 1951). When Pilobolus is kept in an LD cycle of 12:12 and released to constant light, the rhythm rapidly dampens, whereas it continues when released to DD. Rhythmicity in DD also persists after release from several days in LL. Although spore shooting is arrhyth-

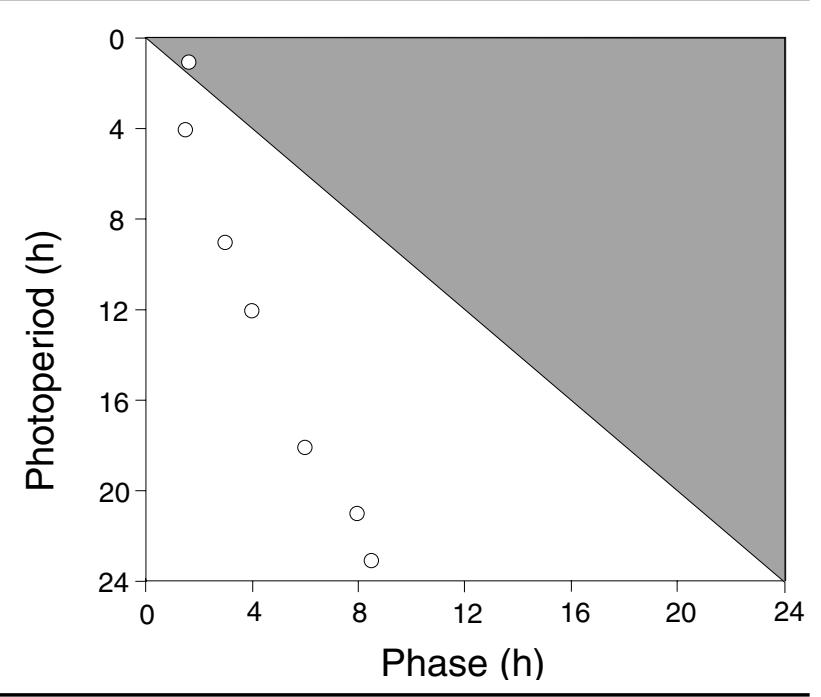

Figure 1. Phase angle of the sporulation maximum of Pilobolus spaerosphorus in different photoperiods (drawn after Uebelmesser, 1954).

mic in LL, the amount of spores shot is 20 -fold compared with DD. At the same time that Schmidle published his findings, Esther-Ruth Uebelmesser (1954) dedicated her thesis work to the same subject. Her thesis is remarkable in many ways. Many of her experiments anticipated circadian protocols, frequently used in later years (different T-cycles and photoperiods, reciprocity, night interruption experiments, entrainment by temperature cycles, etc.). Although she did not fully exploit the richness of her experimental approaches in her interpretations, she must be considered a pioneer of the field and has certainly inspired Colin Pittendrigh to use Pilobolus as a circadian model system (Bruce et al., 1960). Probably, Pittendrigh abandoned this model system because of the unbearable smell penetrating the laboratory when the bovine dung media was prepared (Michael Menaker and Gene Block, personal communication, December 2000).

Uebelmesser reported species-specific phase angles in LD cycles (P. sphaerosphorus peaks at ZT 03, $P$. crystallinus at ZT 08). Unlike Klein's (1948) earlier report, the rhythm was observed in all photoperiods (except for LL) with a systematically different phase angle (Fig. 1). Uebelmesser also showed that the Pilobolus circadian system is capable of multiplication: When the zeitgeber was near a multiple of the endogenous period (e.g., LD 1:47), sporulation peaked twice every cycle.

She also investigated the ranges of entrainment and found that synchronization persisted in 29-h cycles (both LD 2:27 and 17:12). She submitted Pilobolus sys- 
tematically to symmetrical LD cycles, ranging from 18:18 down to 2:2. While in Neurospora accumulation of conidia (conidial bands) appears to be driven in these protocols with a constant phase angle in reference to lights-off (Fig. 2A; Merrow et al., 1999), the phase angle of the spore-shooting rhythm in Pilobolus was systematically different with changing cycle lengths (Fig. 2B), possibly reflecting circadian entrainment. Closer investigation, however, revealed that the Pilobolus sporulation rhythm is also driven by the LD cycle, but unlike in Neurospora, by lights-on. Sporulation in Pilobolus is triggered by light, and the spores mature for approximately $28 \mathrm{~h}$ before they are shot (see arrows in Fig. 2B and C). The maturation time represents a kind of memory capacity for prior events. This is seen in experiments in which the fungi were released to DD (e.g., from LD 4:4 shown in Fig. 2C). The rhythm, synchronized to a given light cycle, persists for another $28 \mathrm{~h}$ until the endogenous circadian control takes over. Thus, depending on conditions, the production of asexual spores in Pilobolus is controlled both by the clock (phase angle) and by light (a driven spore release once per LD cycle).

Fungal circadian clocks can be exquisitely light sensitive, concerning both fluence and duration. The Pilobolus clock requires no more than half a millisecond of light to be completely reset (Bruce et al., 1960), and in Neurospora conidial banding is driven by light fluences down to moonlight levels (Merrow et al., 1999). In Neurospora crassa, conidial banding occurs about once per $22 \mathrm{~h}$ in DD. In LL, the banding pattern stops (following a transient suppression of conidiation by light), a phenomenon that has been observed in many fungi. Light appears to stop the circadian system completely, an observation supported by nonrhythmic, elevated clock gene expression in LL (Crosthwaite et al., 1995), in addition to a set phase relationship of the free-running circadian rhythm on release to DD.

Sordaria fimicola and Daldinia concentrica (both also Ascomycetes, like Neurospora) show circadian rhythms in sexual spore shooting in $\mathrm{DD}$, which are entrainable in LD (Austin, 1968; Ingold and Cox, 1955). In Daldinia, circadian rhythmicity persists in LL, though it damps after several days-in Sordaria, LL appears to suppress rhythmic release (Austin, 1968). Interestingly, S. fimicola shares a functional frequency (frq) ortholog, relative to N. crassa (Merrow and Dunlap, 1994), suggesting mechanistic similarities in the photobiology and in the circadian programs of these species. Like Daldinia, spore release of the Basidiomycete Pellicularia
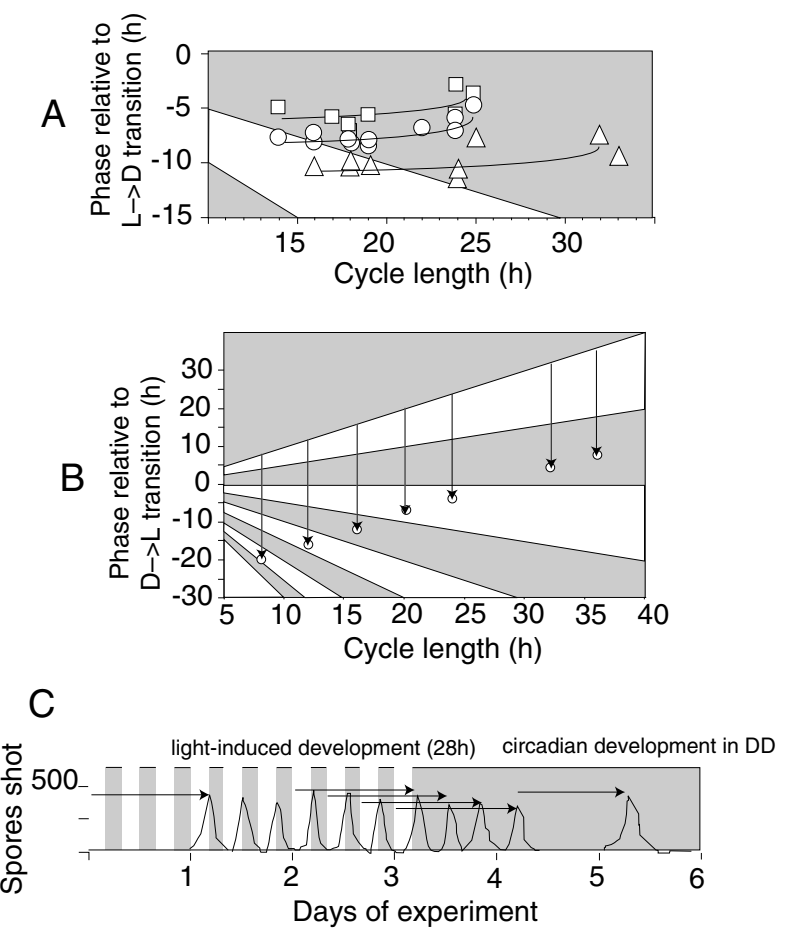

Figure 2. Entrainment of rhythmicity in symmetrical LD cycles. (A) In Neurospora, the phase angle of the conidiation rhythm relative to the light $\rightarrow$ dark transition is specific for the different $f r q$ strains (circles: $f r q+$ period $=22 \mathrm{~h}$; squares: $f r q 1$ - period $=16 \mathrm{~h}$; triangles $f r q 7$ - period $=29 \mathrm{~h}$ ) and is independent of $\mathrm{T}$ (except in longer T-cycles). Conidiation starts after approximately one third of the circadian period, as determined in DD (redrawn after Merrow et al., 1999). (B, C) Phase angles of the Pilobolus spore-shooting rhythm in symmetrical LD cycles. The rhythm is driven by the onset of light $28 \mathrm{~h}$ earlier. This span represents the time that spores take to mature when triggered by light. When released to DD, the rhythm synchronized by the light cycle persists for another $28 \mathrm{~h}$, when the cultures initiate a self-sustained rhythm under circadian control (e.g., release from LD 4:4 in panel B). Data from Uebelmesser (1954).

filamentosa is circadian in either LL or DD and entrainable by LD cycles (Carpenter, 1949). There are also species that show rhythmicity in LD but neither in LL nor DD (e.g., Pyricularia; see Barksdale and Asai, 1961), indicating that sporulation is not always controlled by a circadian clock. Among the fungal organisms in the Protocistic kingdom, reports for rhythmic spore discharge have only been published for the Oomycota (e.g., Phytophthora; see Hirst, 1953). Considering that fungi are in many cases plant or animal pathogens, the observations that their reproductive success depends on the light regime is of high practical importance (e.g., the oat pathogen Erysiphe graminis produces many fewer spore-forming structures in constant light, relative to DD or LD; see Carver et al., 1994). 


\section{SEASONALITY AND PHOTOPERIODISM IN FUNGI}

There can be no doubt that the reproduction of fungi is just as seasonal as in other organisms, especially if they live far enough away from the equator. Like in other poikilotherms, fungal seasonality will be controlled both by photoperiod and by temperature. The interplay between these factors has been extensively studied in insects (Pittendrigh et al., 1991). Any collector or gourmet of mushrooms knows that the appearance of fungal fruiting bodies is restricted to certain times of the year. The concentration of spores (most frequently assessed by air filtration) also changes drastically over the course of a year (see examples in Fig. 3). These annual rhythms are thought to be correlated directly to environmental conditions such as available nutrients, humidity, wind speed, or temperature (Ingold, 1971). Some fungi can consolidate rhythmicity in reproduction with nondaily and nonannual periodicities (cf. Ingold, 1971). The discharge of glebal mass from a fruiting culture of Sphaerobolus stellatus in constant conditions oscillates in a 10- to 12-day rhythm when grown in LL at $20^{\circ} \mathrm{C}$. This infradian reproduction rhythm is, like so many other rhythmic processes, based on negative feedback (Ingold and Nawaz, 1967b). The interval between peaks correlates with the time span "from the first visible initiation of sporosphores to maturity, and suggests that existing fruit-bodies inhibit the development of new ones" (Ingold, 1971, p 215).

As with many photoperiodic plants, some diurnal sporulators require light induction followed by a dark period to initiate their seasonal reproduction (Durand, 1982; Leach, 1967). As with short-day plants, their maturation process is exquisitely light sensitive and is inhibited when a short light pulse (in the range of seconds) interrupts the required dark period (Durand, 1982), with the timing of the light pulse and the length of the dark period crucial for the inhibitory effect.

While there is no question about seasonality in fungi, investigations into photoperiodic mechanisms and/or photoperiodic memory are very sparse. For reasons of economic incentive, many of the investigations into the influence of photoperiod on fungal development and reproduction concern host-infecting pathogens. When the entomopathogenic (insect-infecting) fungus Metarhizium anisopliae is grown in different temperatures $\left(25,28\right.$, and $\left.30^{\circ} \mathrm{C}\right)$ and photoperiods $(24,16,12$, and $8 \mathrm{~h})$, its colony size

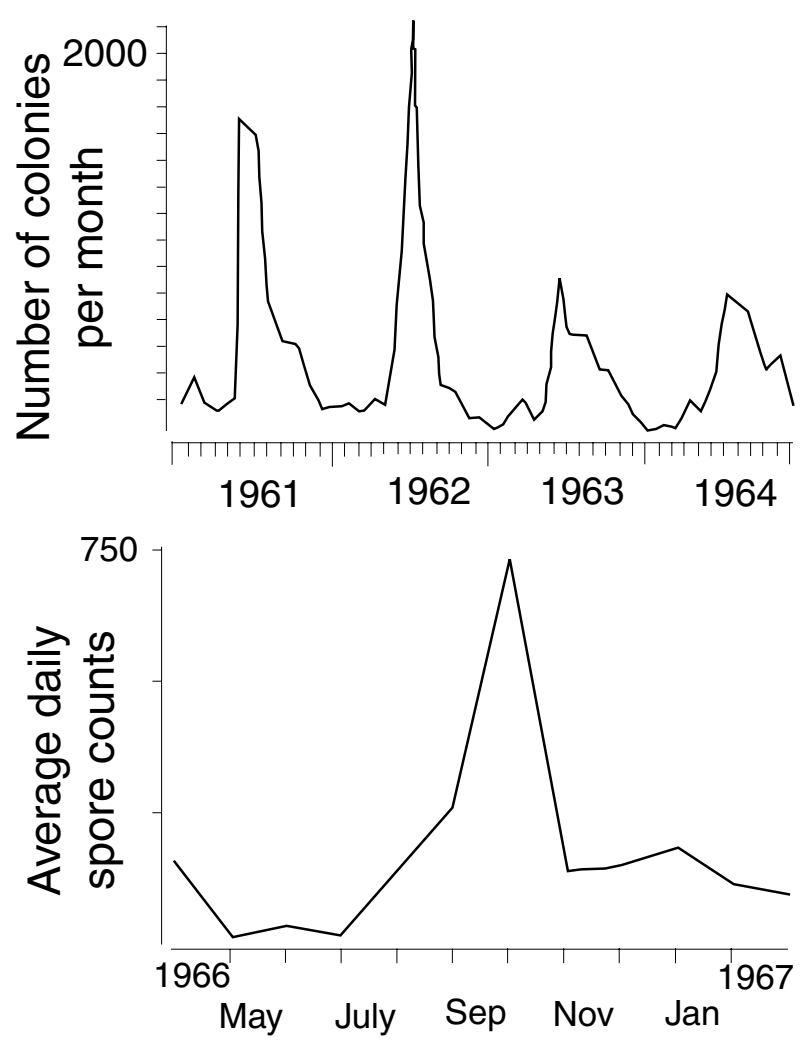

Figure 3. Annual distributions of (sexual) ascospores in the air. Examples shown for Cladosporium collected in Wales with maximum concentrations in June (top, redrawn from Harvey, 1967) and for Hypoxylon rubiginosum with a maximum in October (bottom, redrawn from Hodgkiss and Harvey, 1969).

and the number of spores produced are maximal at $28^{\circ} \mathrm{C}$ and a day length of $16 \mathrm{~h}$ (Alves et al., 1984). Linear mycelial growth in Colletotrichum manihotis (a plant pathogen from the Congo) is greater in DD than in LL (Makambila, 1984). The inhibitory effect of light depends on photoperiod, as it is less in LD 12:12 compared with longer and shorter photoperiods. The amplitude of this photoperiodic response increases with light fluence and temperature and is absent at lower temperatures $\left(20^{\circ} \mathrm{C}\right)$. The formation of chlamydospores (thick-walled, asexual resting spores) of the corn pathogen Exserohilum turcicum is also affected by photoperiod and temperature (Levy, 1995). In addition to photoperiodic effects on growth and asexual spore formation, day or night length can also modify the development of sexual spores. The formation of perithecia in Mycosphaerella pinodes, for example, favors temperatures around $20^{\circ} \mathrm{C}$ and a $16 \mathrm{~h}$ photoperiod when grown under controlled laboratory conditions (Roger and Tivoli, 1996). 
This incomplete list of the effects of photoperiod on fungal propagation and reproduction mainly concerns species that are either difficult to study in the laboratory or that have not been characterized genetically and are not readily transformable. Proof for the involvement of the circadian system or the existence of a photoperiodic memory will involve a wide range of experiments, ranging from a good characterization of the organism's circadian system and its photobiology, as well as photoperiodic response curves, night-interruption, and Nanda-Hamner type experiments (systematic light cycles with long nights, up to cycle lengths of several days; Nanda and Hamner, 1958), with an organism that has good genetics and transformation possibilities.

\section{NEUROSPORA-A POTENTIAL MODEL SYSTEM FOR PHOTOPERIODIC RESEARCH}

A good candidate for such an approach is Neurospora crassa. It is amenable to biochemical, molecular, genetic, and physiological experiments, and it can easily be grown in large quantities. The sequence of its haploid genome is complete (http://www-genome.wi.mit.edu/annotation/ fungi/neurospora/, http://www.mips.biochem. mpg.de/proj/neurospora/) and microarrays are in production. Many mutants have been characterized and are available. In addition, it constitutes one of the pioneer model systems, both for the circadian clock and photobiology.

\section{Geoclimatic Environment}

When the three chronobiologists had finished their mushrooms and ordered another Weißbier and some camembert and blue cheese for dessert, they returned to the question of fungal photoperiodism and the prospect that this phenomenon could be best investigated in Neurospora. Yet, doubts were raised whether this fungus, although an excellent model system in many ways, could be useful for photoperiodic studies. "It doesn't live far enough from the equator," was one of the arguments, and "Doesn't it just sit there as a dormant sexual spore, waiting for the next fire?" was another. A subsequent review of the literature weakened these skepticisms. Granted, not a whole lot is known about the life cycle of wild Neurospora throughout the course of the year, but there are indications that sexual and asexual reproduction, dormancy, and growth are segregated over time (Pandit and Maheshwari, 1994). In addition, Neurospora crassa strains have been found over a large range of southern and northern latitudes (Fig. 4). Neurospora intermedia and other Neurospora species have been found as far north as the Canadian border and as far south as New Zealand (Turner et al., 2001). So, the genus Neurospora is found at latitudes corresponding to regions where winter nights and summer days are as long as $16 \mathrm{~h}$ and the winter days and summer nights as short as $8 \mathrm{~h}$. Neurospora, therefore, amends itself to investigations of wild-type strains according to native latitudinal cline similar to the ones performed by Pittendrigh on Drosophila (Pittendrigh, 1993; Pittendrigh et al., 1991).

The large number of N. crassa samples collected in Louisiana and Florida tells us something about their preferred habitat, concerning both nutrition and climate. Neurospora is a pioneer organism after fires have destroyed most of the vegetation, living on the remaining carbon sources (e.g., quinic acid). The strain used by practically all laboratories that study Neurospora was first isolated by Shear and Dodge (1927) from sugar cane bagasse in Louisiana. Although in this region the humidity remains relatively constant over the year (however, with large daily changes), the photoperiod changes even in this southern location $\left(30^{\circ} \mathrm{N}\right)$ by $4 \mathrm{~h}$ over the course of the year, with temperatures ranging from 8 to $34{ }^{\circ} \mathrm{C}$ (Grünewald, 1982). These changes would certainly make it advantageous for Neurospora to anticipate seasons with the help of photoperiodic and/or thermoperiodic mechanisms, especially as they correlate with large differences in rainfall. Latitudes around $30^{\circ}$ actually produce the largest amplitudes in the annual human reproduction rhythm (Roenneberg and Aschoff, 1990).

\section{Chrono- and Photobiology in Neurospora}

Figure 5 shows the components of the Neurospora circadian transcription/translation feedback loop. The products of the two white-collar genes (wc-1 and $w c-2$ ) form a protein complex (WCC) that interacts with the FRQ protein (Denault et al., 2001; Merrow et al., 2001). frq transcription depends on the WHITECOLLAR proteins, and FRQ feeds back negatively on its own expression (Aronson et al., 1994b; Crosthwaite et al., 1997) and positively onto WC-1 levels (Lee et al., 2000; Merrow et al., 2001). An additional "box" in the Neurospora circadian system (Fig. 5, the FLO; McWatters et al., 1999) is indicated by physiological evidence showing entrainment of FRQ-less strains by 


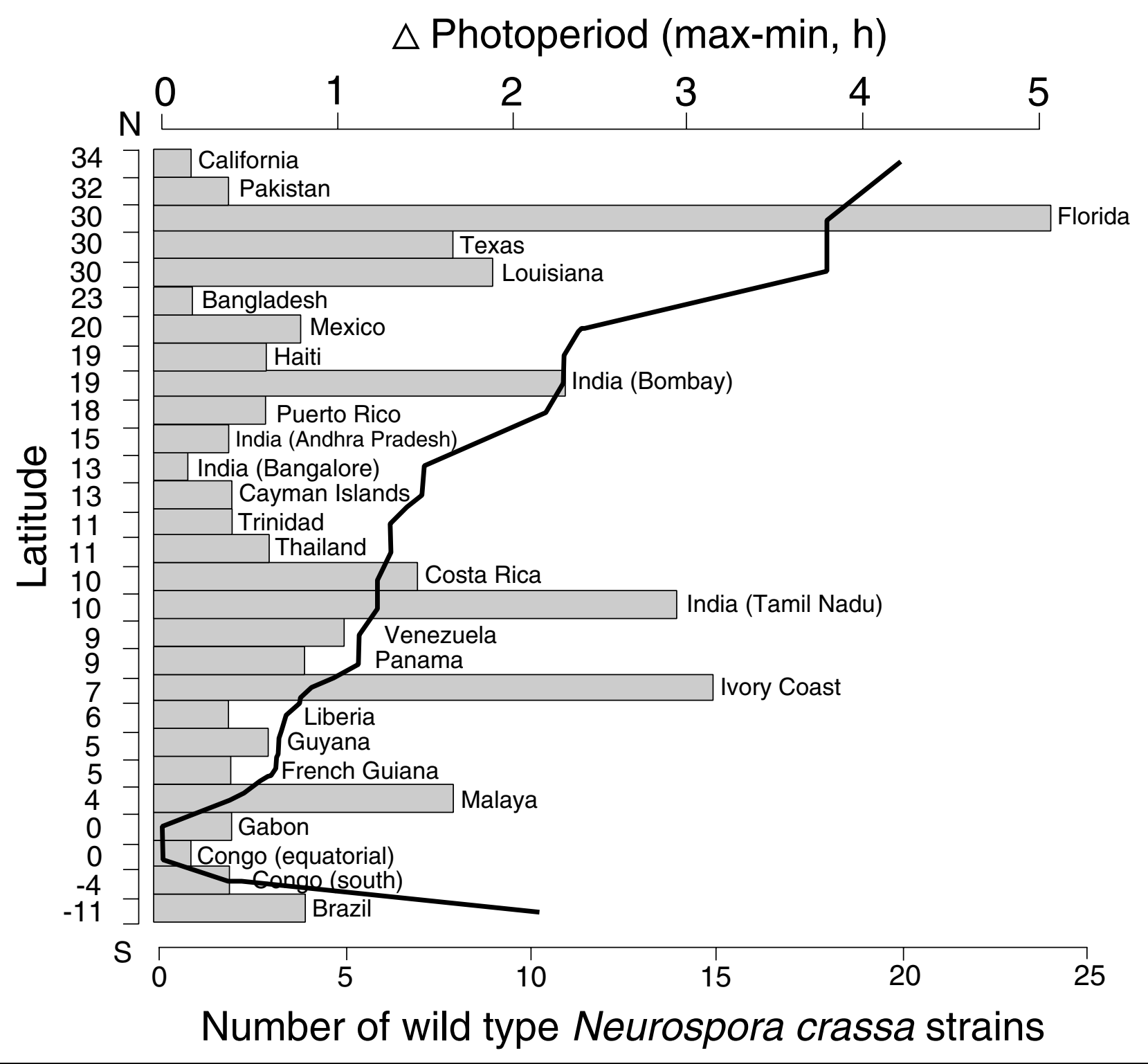

Figure 4. Latitudinal and geographical distribution of the wild-type strains of Neurospora crassa deposited in the Fungal Genetic Stock Center, Kansas (source: http://www.fgsc.net, as well as Metzenberg and Turner et al., 2001). The respective photoperiodic differences between longest and shortest day of the year are drawn as a line (upper horizontal axis).

temperature cycles in the circadian range (Merrow et al., 1999) and also by experiments indicating residual self-sustained oscillations in the absence of FRQ (Aronson et al., 1994a; Lakin-Thomas and Brody, 2000; Loros et al., 1986). These boxes-the transcription/ translation feedback loop and the FLO-may correspond functionally to A and B oscillators in Drosophila, which were modeled to explain different phase-shifting patterns to distinct zeitgeber (Pittendrigh, 1960).

frq was uncovered in circadian mutant hunts, whereas screens for defects in light perception resulted in the isolation of "blind" mutants at two loci, $w c-1$ and $w c-2$ (Degli-Innocenti and Russo, 1984; Harding and Turner, 1981). They were only identified as integral for clock function some years later (Crosthwaite et al., 1997) and are good candidates for photoreceptor molecules in Neurospora. Interestingly, it has been noted that perithecial development, even in darkness, is poor in $w c$ mutants (i.e., in the absence of light responsiveness; Degli-Innocenti and Russo, 1984). This suggests a role for light and/or the clock in the reproductive success of $N$. crassa, something that has been alluded to in the past (Lakin-Thomas et al., 1990). 


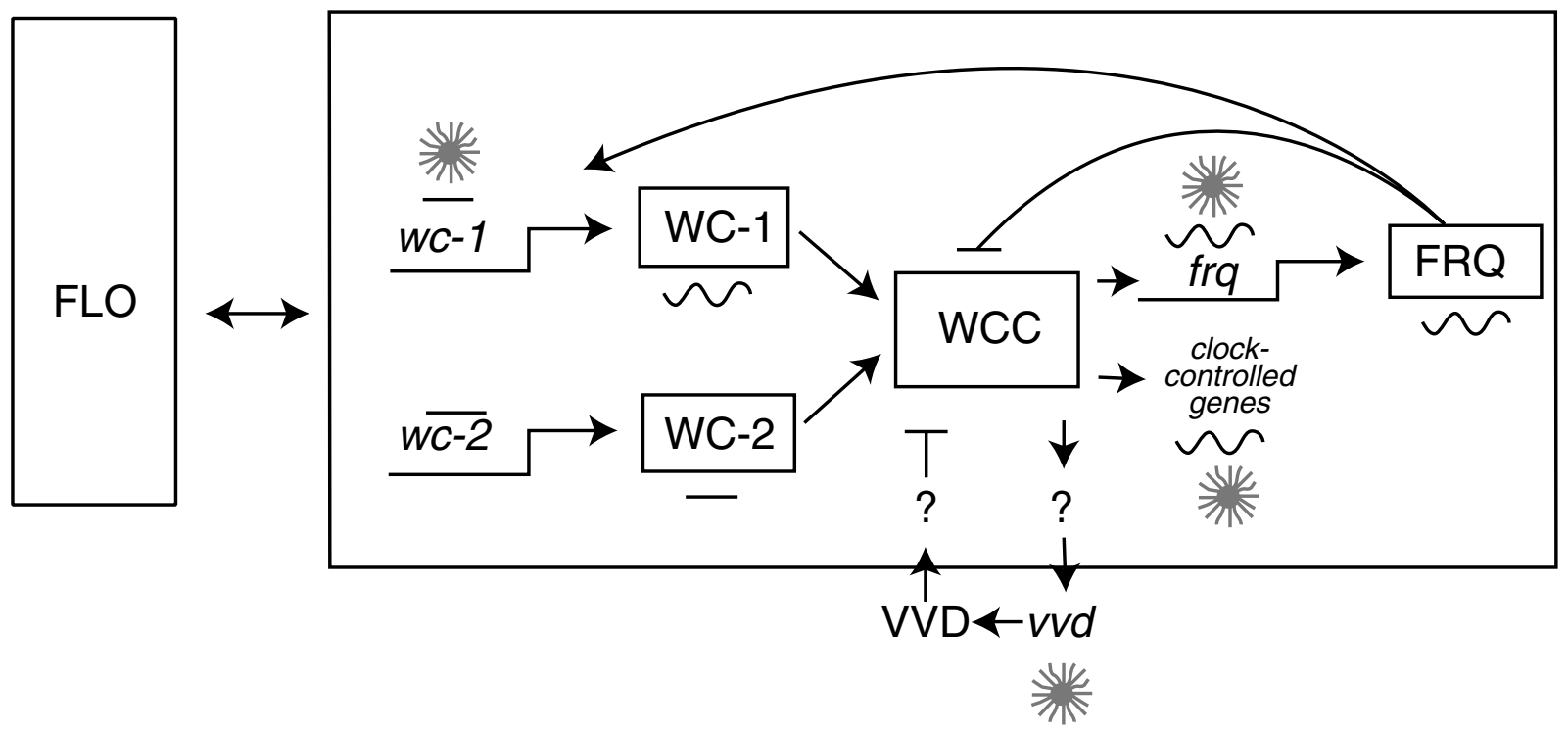

Figure 5. The components of the Neurospora circadian transcription-translation feedback loop. See text for details. Rhythmic or constitutive expressions are indicated by a wiggle or a straight line, respectively, and light inducibility by the sun symbol (redrawn after Merrow and Roenneberg, 2001).

\section{Effects of Photoperiod on Neurospora crassa}

The work of Uebelmesser on Pilobolus included two types of experiments in LD cycles-those in which the length of the LD cycle was changed (with light and darkness each filling half of the cycle) and those in which only the photoperiod was altered in the context of a 24-h-cycle (compare Figs. 1 and 2B). It is quite striking that in the latter type of experiments (Fig. 2 $\mathrm{B}, \mathrm{C})$, the phase angle was driven, with a maximum in spore shooting appearing always $28 \mathrm{~h}$ after an onset of light, whereas the phase angle in the former type of experiments was locked neither to dawn nor dusk. We have observed similar differences in Neurospora. In symmetrical T-cycles (Fig. 2A), bands always begin to form approximately $7 \mathrm{~h}$ after onset of the dark period (one third of circadian period in DD), while experiments in 24-h cycles with differing photoperiods show that the phase distribution of conidiation is not strictly locked to dusk or dawn (Ying Tan, Martha Merrow, and Till Roenneberg, unpublished results; Chang and Nakashima, 1997).

Is there something special about the equinox (regardless of whether it is in the context of $24 \mathrm{~h}$, as in nature, or in experimentally shorter and longer days) or are there other explanations for the different behaviors in the two sets of experiments? The answer probably lies in the interplay of many required factors that apparently control development: maturation time, refractoriness to light, length and timing of the light and dark periods, and circadian control. In the case of Pilobolus (Uebelmesser, 1954), maturation of the asexual spores takes $23.8 \mathrm{~h}$ when controlled by the circadian clock, $25.5 \mathrm{~h}$ when triggered by a 1- or 2-h light period, $29 \mathrm{~h}$ after 16 or $18 \mathrm{~h}$ of light, and as long as $34 \mathrm{~h}$ when the lights are kept on (thus, the length of the triggering light episode is important). Because no further sporulation maxima appear in LL, an additional dark $\rightarrow$ light transition is obviously required, which again must be timed appropriately. When it comes less than $4 \mathrm{~h}$ into maturation, it appears to reset the ongoing maturation so that it can never proceed (hence, arrhythmicity in LD 2:2). When it is placed $4 \mathrm{~h}$ or more into maturation, it triggers a new maturation process that can proceed in parallel to the ongoing one (hence, rhythmicity in LD 4:4 and all longer T-cycles, see Fig. 2 $B$ and $C)$. On the other hand, when the dark $\rightarrow$ light transition is placed too far into maturation (approximately $7 \mathrm{~h}$ before the sporulation peak), it again begins to obstruct normal development, without simply triggering a new maturation process. The complicated interplay of the listed factors can be used to explain the differences between the phase angles of the two sets of experiments in Pilobolus.

Control mechanisms of conidiation in Neurospora are different from Pilobolus. For example, we have never seen the "developmental memory" shown in Figure 2C. Yet, similar factors must also play a role in 
Neurospora development. For example, the WHITECOLLAR-dependent, light-receptive system becomes refractory to additional light for several hours after an initial light signal (Arpaia et al., 1999; Lauter and Yanofsky, 1993; Schmidhauser et al., 1990), and complete resetting of the circadian clock requires light pulses longer than $2 \mathrm{~h}$ (Tan, Merrow, and Roenneberg, unpublished data; Chang and Nakashima, 1997; Dharmananda, 1980). In addition, light signals of different lengths appear to be transduced via different mechanisms. While short light pulses (and the resulting phase shifts) correlate well with the amount of frq RNA produced (Crosthwaite et al., 1995), longer light periods can synchronize conidiation without light-induced frq-transcription, as long as FRQ protein is present (expressed off an inducible light-independent promoter; see Merrow et al., 2001). Also, the rib-1 (riboflavin) and lis (light insensitive) strains allow rhythmic conidiation in constant light, though phase shifting and carotenoid production are intact, albeit sometimes with modest deficits (Paietta and Sargent, 1981, 1983). The regulation of conidiation by light thus has at least two functional components, one that mediates phase shifting and one that contributes to the apparent arrhythmicity in constant light, and these are intertwined with components of the circadian system.

Most photoperiodic response mechanisms measure night rather than day length (Saunders, 1982). For this, some timer must measure the length of darkness (scotoperiod). A likely candidate for measuring scotoperiod in Neurospora is the frq/FRQ system. The Neurospora clock appears to be a pure night clock in the sense that light, down to moonlight levels (Merrow et al., 1999), drives conidiation rhythmicity, possibly by not allowing the decay of frq (Crosthwaite et al., 1995). The decay kinetics of FRQ in darkness depend on the frq allele (Liu et al., 2000). Thus, the sequence of the FRQ protein appears to determine its kinetics leading to (a) strain-specific periods in DD and (b) staggered phase angles in symmetrical LD cycles (Aronson et al., 1994a; Chang and Nakashima, 1997; Liu et al., 2000; Merrow et al., 1999). The prediction would be that possible photoperiodic mechanisms are also strain specific (i.e., requiring different photoperiods or the same proportional photoperiods in different cycle lengths for the same response in the different frq mutant strains) and will be absent in FRQ-less strains, similar to what has been shown in period mutants in plants (reviewed in Roenneberg and Merrow, 2000).

\section{Effects of Thermoperiod on Neurospora crassa}

Unlike in mammalian photoperiodism, temperature will play an important role in fungal photoperiodism. The Neurospora circadian system (Merrow et al., 1999), its responsiveness to light (Gooch et al., 1994; Nakashima and Feldman, 1980), and the levels of frq RNA and FRQ protein (Liu et al., 1998) are strongly affected by temperature (although the circadian period is temperature compensated in the intact system; Feldman and Hoyle, 1973). We have shown that Neurospora can be entrained in the circadian range to temperature cycles even without the expression of FRQ protein (Merrow et al., 1999), indicating that circadian qualities exist in Neurospora outside of the frq/FRQ feedback loop (Fig. 5: by the FLO or $\mathrm{B}$ oscillator). In addition, the circadian system is light-blind in FRQ-less strains (Chang and Nakashima, 1997; Lakin-Thomas and Brody, 2000; Merrow et al., 1999), while other light responses remain intact (Merrow et al., 2001). It will be interesting to see what role FRQ plays as a constitutively expressed versus a regulated protein in measuring night length and how it transduces this information to reproductive development. The use of temperature will be an important tool for these studies.

\section{At the End of the Day...}

The distinction between light reception (the first requirement for photoperiodism) and the circadian system (the second requirement) is becoming less clear in all molecular genetic model systems for circadian rhythms research. In plants, photoreceptor mutants have altered free-running periods and the strength of light-induction of RNA is modulated by the circadian system (Anderson et al., 1997; Somers et al., 1998). In Neurospora, the white-collar genes are integral to the circadian clock (Crosthwaite et al., 1997), and frq, previously considered only essential for the circadian system, is an absolute requirement for light-regulated conidiation (see Fig. 5; Chang and Nakashima, 1997; Lakin-Thomas and Brody, 2000; Merrow et al., 1999). As in plants, numerous lightinduced responses in Neurospora are modulated by the circadian system (Heintzen et al., 2001; Merrow et al., 2001). Straightforward fluence titration experiments indicate that the light input pathway is branched: regulated conidation requires less light than does carotenoid induction (Merrow et al., 2001). Based on 
these collective data, it is not clear how separable light input pathways are from circadian transcription/ translation loop. But N. crassa is clearly a powerful molecular genetic system with which to probe these questions.

Recently, scientists have begun to investigate the molecular mechanisms of photoperiodism in mammals (see review in Daan et al., 2001; Hastings, 2001). Earlier work has shown that "clock genes" may or may not be involved in insect photoperiodism: the Drosophila per gene has systematic sequence differences according to latitude, corresponding functionally to temperature compensation of the circadian system (Sawyer et al., 1997), yet photoperiodic response curves and Nanda-Hamner type experiments determined that photoperiodic responses remain intact in per $^{0}$ flies (Saunders, 1990) (but see Tauber and Kyriacou, 2001 [this issue]). Many of these classical circadian experiments remain to be performed with Neurospora, and these will strengthen it as an experimental system for photoperiodism.

\section{ACKNOWLEDGMENTS}

This review is dedicated to Esther-Ruth Uebelmesser, whose work we discovered in the course of researching about seasonality in fungi. Although not widely known, she must be considered as one of the circadian pioneers. We would like to thank Drs. Robert L. Metzenberg and David D. Perkins for sharing many pieces of information as well as Drs. C. P. Kyriacou and P. Lakin-Thomas for helpful conversations. Our work is supported by the Deutsche Forschungsgemeinschaft, Friedrich-Baur-Stiftung, Meyer-Struckmann-Stiftung, and Eppendorf.

\section{REFERENCES}

Alves SB, Risco SH, and Almeida LC (1984) Influence of photoperiod and temperature on the development and sporulation of Metarhizium anisopilae. (Metsch.) Sorok Z ang Ent 97:127-129.

Anderson SL, Somers DE, Millar AJ, Hanson K, Chory J, and Kay SA (1997) Attenuation of phytochrome A and B signaling pathways by the Arabidopsis circadian clock. Plant Cell 9:1727-1743.

Aronson BD, Johnson KA, and Dunlap JC (1994a) The circadian clock locus frequency: A single ORF defines period length and temperature compensation. Proc Natl Acad Sci U S A 91:7683-7687.

Aronson BD, Johnson KA, Loros JJ, and Dunlap JC (1994b) Negative feedback defining a circadian clock:
Autoregulation of the clock gene frequency. Science 263:1578-1584.

Arpaia G, Cerri F, Baima S, and Macino G (1999) Protein kinase $C$ may be a novel component of the blue light transduction pathway in Neurospora crassa. Mol Gen Genet 262:314-322.

Austin B (1968) An endogenous rhythm of spore discharge in Sordaria fimicola. Ann Bot 32:261-278.

Barksdale TH and Asai GN (1961) Diurnal spore release of Piricularia oryzea from rice leaves. Phytopathology 51:313-317.

Berjarano ER, Avalos J, Lipson ED, and Cerda-Olmeda E (1990) Photoinduced accumulation of carotene in Phycomyces. Planta 183:1-9.

Brook PJ (1969) Stimulation of Ascospore release in Venturia inaequalis by far red light. Nature 222:390-392.

Bruce VC, Weight F, and Pittendrigh CS (1960) Resetting the sporulation rhythm in Pilobolus with short light flashes of high intensity. Science 131:728-730.

Calpouzos L and Chang H (1971) Fungus spore germination inhibited by blue and far red radiation. Plant Physiol 47:729-730.

Carpenter JB (1949) Production and discharge of basidiospores of Pellicularia filamentosa (Pat.) Rogers on Hevea rubber. Phytopathology 39:980-985.

Carver TL, Ingerson-Morris SM, Thomas BJ, and Gay AP (1994) Light-mediated delay of primary haustorium formation by Erysiphe graminis f. sp avenae. Physiol Mol Plant Pathol 45:59-79.

Chang B and Nakashima H (1997) Effects of light-dark cycles on the circadian conidiation rhythm in Neurospora crassa. J Plant Res 110:449-453.

Crosthwaite SK, Dunlap JC, and Loros JJ (1997) Neurospora $w c-1$ and $w c-2$ : Transcription, photoresponses, and the origin of circadian rhythmicity. Science 276:763-769.

Crosthwaite SK, Loros JJ, and Dunlap JC (1995) Light-induced resetting of a circadian clock is mediated by a rapid increase in frequency transcript. Cell 81: 1003-1012.

Daan S, Albrecht U, van der Horst GTJ, Illnerová H, Roenneberg T, Wehr TA, and Schwartz WJ (2001) Assembling a clock for all seasons: Are there $\mathrm{M}$ and E oscillators in the genes? J Biol Rhythms 16:105-116.

De Fabo EC, Harding RW, and Shropshire W Jr (1976) Action spectrum between 260 and 800 nanometers for the photoinduction of carotenoid biosynthesis in Neurospora crassa. Plant Physiol 57:440-445.

Degli-Innocenti F and Russo VE (1984) Isolation of new white collar mutants of Neurospora crassa and studies on their behavior in the blue light-induced formation of protoperithecia. J Bacteriol 159:757-761.

Delbruck M, Katzir A, and Presti D (1976) Responses of phycomyces indicating optical excitation of the lowest triplet state of riboflavin. Proc Natl Acad Sci U S A 73:1969-1973.

Denault DL, Loros JJ, and Dunlap JC (2001) WC-2 mediates WC-1-FRQ interaction within the PAS protein-linked circadian feedback loop of Neurospora. EMBO J 20:109-117.

Dharmananda S (1980) Studies of the circadian clock of Neurospora crassa: Light-induced phase shifting, PhD thesis, University of California, Santa Cruz, CA. 
Durand R (1982) Photoperiodic response of Coprinus congregatus: Effects of light breaks on fruiting. Physiol Plant 55:226-230.

Edmunds LN Jr, Apter RI, Rosenthal PJ, Shen W-K, and Woodward JR (1979a) Light effects in yeast: Persisting oscillations in cell division activity and amino acid transport in cultures of Saccharomyces cerevisiae entrained by light:dark cycles. Photochem Photobiol 30:595-601.

Edmunds LN Jr, Ulaszewski S, Mamouneas T, Shen W-K, Rosenthal PJ, Woodward JR, and Cirillo VP (1979b) Light effects in yeast: Evidence for participation of cytochromes in photoinhibition of growth and transport in Saccharomyces cerevisiae cultured at low temperatures. J Bacteriol 138:523-529.

Edmunds LN Jr, Woodward JR, and Cirillo VP (1978) Light effects in yeast: Inhibition by visible light of growth and transport in Saccharomyces cerevisiae grown at low temperatures. J Bacteriol 133:692-698.

Feldman JF and Hoyle MN (1973) Isolation of circadian clock mutants of Neurospora crassa. Genetics 75:605-613.

Gooch VD, Wehseler RA, and Gross CG (1994) Temperature effects on the resetting of the phase of the Neurospora circadian rhythm. J Biol Rhythms 9:83-94.

Grünewald G (1982) Länder und Klima. Texte und Tabellen. F. A. Brockhaus, Wiebaden.

Harding RW and Turner RV (1981) Photoregulation of the carotenoid biosynthetic pathway in albino and white collar mutants of Neurospora crassa. Plant Physiol 68:745-749.

Harvey R (1967) Air-spore studies at Cardiff I. Cladosporium. Trans Br Mycol Soc 50:479-495.

Hastings M (2001) Modeling the molecular calendar. J Biol Rhythms 16:117-123.

Heintzen C, Loros JJ, and Dunlap JC (2001) The PAS protein VIVID defines a clock-associated feedback loop that represses light input, modulates gating, and regulates clock resetting. Cell 104:453-464.

Hirst JM (1953) Changes in atmospheric spore content: Diurnal periodicity and the effects of weather. Trans Br Mycol Soc 36:375-393.

Hodgkiss IJ and Harvey R (1969) Spore discharge rhythms in Pyrenomycetes: VI. The effect of climatic factors on seasonal and diurnal periodicities. Trans $\mathrm{Br}$ Mycol Soc 52:355-363.

Huala E, Oeller PW, Liscum E, Han I-S, Larsen E, and Briggs WR (1997) Arabidopsis NPH1: A protein kinase with a putative redox-sensing domain. Science 278:2120-2123.

Ingold CT (1971) Periodicity. In Fungal Spores, pp 214-238, Oxford University Press, London.

Ingold CT and Cox VJ (1955) Periodicity of spore discharge in Daldinia. Ann Bot 29:201-209.

Ingold CT and Nawaz M (1967a) Sporophore development in Sphaerobolus: Effect of blue and red light. Ann Bot 31:469-477.

Ingold CT and Nawaz M (1967b) Sporophore production in Spaerobolus with special reference to periodicity. Ann Bot 31:791-802.

Kippert F, Engelmann W, and Ninnemann W (1991a) "Blind" cytochrome b mutants of yeast can still be entrained to 24 hour temperature cycles. J Interdisc Cycle Res 22:137.
Kippert F, Ninnemann H, and Engelmann W (1991b) Photosynchronization of the circadian clock of Schizosaccharomyces pombe: Mitochondrial cytochrome b in an essential component. Curr Genet 19:103-107.

Klein D (1948) Influence of varying periods of light and dark on asexual reproduction of Pilobolus kleinii. Bot Gaz 110:139.

Lakin-Thomas PL and Brody S (2000) Circadian rhythms in Neurospora crassa: Lipid deficiencies restore robust rhythmicity to null frequency and white-collar mutants. Proc Natl Acad Sci U S A 97:256-261.

Lakin-Thomas PL, Coté GG, and Brody S (1990) Circadian rhythms in Neurospora crassa: Biochemistry and genetics. Crit Rev Microbiol 17:365-416.

Lauter F-R and Yanofsky C (1993) Day/night and circadian rhythm control of con gene expression in Neurospora. Proc Natl Acad Sci U S A 90:8249-8253.

Leach CM (1967) Interaction of near-ultraviolet and temperature on sporulation of the fungi Alternaria, Cercosporella, Fusarium, Helminthosporium, and Stemphylium. Can J Bot 45:1999-2016.

Leach CM (1968) An action spectrum for light inhibition of the "terminal phase" of photosporogenesis in the fungus Stemphylium bortyosum. Mycolcogia 60:532-546.

Lee K, Loros JJ, and Dunlap JC (2000) Interconnected feedback loops in the Neurospora circadian system. Science 289:107-110.

Levy Y (1995) Inoculum survival of Exserohilum turcicum on corn between and during growing periods. Can J Plant Pathol 17:144-146.

Linden H, Ballario P, Arpaia G, and Macino G (1999) Seeing the light: News in Neurospora blue light signal transduction. Adv Genet 41:35-54.

Liu Y, Loros J, and Dunlap JC (2000) Phosphorylation of the Neurospora clock protein FREQUENCY determines its degradation rate and strongly influences the period length of the circadian clock. Proc Natl Acad Sci U S A 97:234-239.

Liu Y, Merrow M, Loros JL, and Dunlap JC (1998) How temperature changes reset a circadian oscillator. Science 281:825-829.

Loros JJ, Richman A, and Feldman JF (1986) A recessive circadian clock mutation at the frq locus of Neurospora crassa. Genetics 114:1095-1110.

Makambila C (1984) Étude de quelques interactions de la lumière et de la temperature sur la croissance linére et la sporulation chez Colletotrichum manihotus Henn. ФYTON 1984:1-7.

Margulis L and Schwartz KV (1988) Five Kingdoms, W. H. Freeman, New York.

Martinez-Garcia JF, Huq E, and Quail PH (2000) Direct targeting of light signals to a promoter element-bound transcription factor. Science 288:859-863.

McWatters H, Dunlap JC, and Millar AJ (1999) Circadian biology: Clocks for the real world. Curr Biol 9:R633-R635.

Merrow M, Brunner M, and Roenneberg T (1999) Assignment of circadian function for the Neurospora clock gene frequency. Nature 399:584-586.

Merrow M, Franchi L, Dragovic Z, Görl M, Johnson J, Brunner M, Macino G, and Roenneberg T (2001) Circadian reg- 
ulation of the light input pathway in Neurospora crassa. EMBO J 20:307-315.

Merrow M and Roenneberg T (2001) The circadian cycle: Is the whole greater than the sum of its parts? Trends Genet 17:4-7.

Merrow MW and Dunlap JC (1994) Intergeneric complementation of a circadian rhythmicity defect: Phylogenetic conservation of structure and function of the clock gene frequency. EMBO J 13:2257-2266.

Mooney JL and Yager LN (1990) Light is required for conidiation in Aspergillus nidulans. Genes Dev 4:14731482.

Nakashima H and Feldman J (1980) Temperature sensitivity of light-induced phase shifting of the circadian clock of Neurospora. Photochem Photobiol 32:247-251.

Nanda KK and Hamner KC (1958) Studies on the nature of the endogenous rhythm affecting photoperiodic response of Biloxi soybean. Bot Gaz 120:14-25.

Ninnemann H (1991) Participation of the molybdenum cofactor of nitrate reductase from Neurospora crassa in light promoted conidiation. J Plant Physiol 137:677-682.

Nunes MV and Saunders DS (1999) Photoperiodic time measurement in insects: A review of clock models. J Biol Rhythms 14:84-104.

Paietta J and Sargent ML (1981) Photoreception in Neurospora crassa: Correlation of reduced light sensitivity with flavin deficiency. Proc Natl Acad Sci U S A 78:5573-5577.

Paietta J and Sargent ML (1983) Isolation and characterization of light-insensitive mutants of Neurospora crassa. Genetics 104:11-21.

Pandit A and Maheshwari R (1994) Sexual reproduction by Neurospora in nature. Fungal Genetics Newsletter 41:67-68.

Pittendrigh CS (1960) Circadian rhythms and the circadian organization of living systems. Cold Spring Harb Symp Quant Biol 25:159-184.

Pittendrigh CS (1993) Temporal organization: Reflections of a Darwinian clock-watcher. Annu Rev Physiol 55:17-54.

Pittendrigh CS, Kyner WT, and Takamura T (1991) The amplitude of circadian oscillators: Temperature dependence, latitudinal clines, and the photoperiodic time measurement. J Biol Rhythms 6:299-314.

Roenneberg T and Aschoff J (1990) Annual rhythm of human reproduction: II. Environmental correlations. J Biol Rhythms 5:217-240.

Roenneberg T and Merrow M (2000) Circadian light input: Omnes viae Romam ducunt. Curr Biol 10:R742-R745.
Roger C and Tivoli B (1996) Effect of culture medium, light and temperature on sexual and asexual reproduction of four strains of Mycosphaerella pinodes. Mycol Res 100:304-306.

Russo VE (1988) Blue light induces circadian rhythms in the $b d$ mutant of Neurospora: Double mutants $b d, w c-1$ and $b d, w c-2$ are blind. Photochem Photobiol 2:59-65.

Sargent ML, Briggs WR, and Woodward DO (1956) Circadian nature of a rhythm expressed by an invertaseless strain of Neurospora crassa. Plant Physiol 41:1343-1349.

Saunders DS (1982) Insect Clocks, 2nd ed, Pergamon, Oxford, UK.

Saunders DS (1987) Insect photoperiodism: The linden bug, Phyrrhocoris apterus, a species that measures day length rather than night length. Experientia 43:935-937.

Saunders DS (1990) The circadian basis of ovarian diapause regulation in Drosophila melanogaster: Is the period gene causally involved in photoperiodic time measurement? J Biol Rhythms 5:315-332.

Sawyer LA, Hennessy JM, Peixoto AA, Rosato E, Parkinson $\mathrm{H}$, Costa R, and Kyriacou CP (1997) Natural variation in a Drosophila clock gene and temperature compensation. Science 278:2117-2120.

Schmidhauser TJ, Lauter FR, Russo VE, and Yanofsky C (1990) Cloning, sequence, and photoregulation of $a l-1$, a carotenoid biosynthetic gene of Neurospora crassa. Mol Cell Biol 10:5064-5070.

Schmidle A (1951) Die Tagesperiodizität der asexuellen Reproduktion von Pilobolus spaerosporus. Arch Mikrobiol 16:80-100.

Shear CL and Dodge BO (1927) Life histories and heterothallism of the red bread-mold fungi of the Monilia sitophila group. J Agric Res 34:1019-1042.

Somers DE, Devlin PF, and Kay SA (1998) Phytochromes and cryptochromes in the entrainment of the Arabidopsis circadian clock. Science 282:1488-1490.

Tauber E and Kyriacou CP (2001) Insect photoperiodism and circadian clocks: Models and mechanisms. J Biol Rhythms 16:381-390.

Turner BC, Perkins DD, and Farifield A (2001) Neurospora from natural populations: A global study. Fung Gen Biol, 32:67-92.

Uebelmesser E-R (1954) Über den endogenen Tagesrhythmus der Sporangienbildung von Pilobolus. Arch Mikrobiol 20:1-33.

West DJ (1976) Phase shifting of circadian rhythm of conidiation in response to ultraviolet light. Neurospora Newsletter 23:17-18. 